\title{
The impact of milk proteins and peptides on blood pressure and vascular function: a review of evidence from human intervention studies
}

\author{
Ágnes A. Fekete ${ }^{1,2 *}$, D. Ian Givens ${ }^{2}$ and Julie A. Lovegrove ${ }^{1}$ \\ ${ }^{1}$ Hugh Sinclair Unit of Human Nutrition and Institute for Cardiovascular and Metabolic Research (ICMR), Department of \\ Food and Nutritional Sciences, Faculty of Life Sciences, University of Reading, Reading RG6 GAR, UK \\ ${ }^{2}$ Food Production and Quality Research Division, Faculty of Life Sciences, School of Agriculture, Policy and Development, \\ University of Reading, Reading RG6 GAR, UK
}

\section{Abstract}

CVD are the leading cause of death worldwide. Hypertension, a major controllable risk factor of CVD, is intimately associated with vascular dysfunction, a defect which is also now recognised to be a major, modifiable risk factor for the development of CVD. The purpose of the present review was to critically evaluate the evidence for the effects of milk proteins and their associated peptides on blood pressure (BP) and vascular dysfunction. After a detailed literature search, the number of human trials evaluating the antihypertensive effects of caseinderived peptides (excluding isoleucine-proline-proline and valine-proline-proline) was found to be limited; the studies were preliminary with substantial methodological limitations. Likewise, the data from human trials that examined the effects of whey protein and peptides were also scarce and inconsistent. To date, only one study has conducted a comparative investigation on the relative effects of the two main intact milk proteins on BP and vascular function. While both milk proteins were shown to reduce BP, only whey protein improved measures of arterial stiffness. In contrast, a growing number of human trials have produced evidence to support beneficial effects of both milk proteins and peptides on vascular health. However, comparison of the relative outcomes from these trials is difficult owing to variation in the forms of assessment and measures of vascular function. In conclusion, there is an accumulating body of evidence to support positive effects of milk proteins in improving and/or maintaining cardiovascular health. However, the variable quality of the studies that produced this evidence, and the lack of robust, randomised controlled intervention trials, undermines the formulation of firm conclusions on the potential benefits of milk proteins and peptides on vascular health.

\section{Key words: Milk proteins: Peptides: CVD: Blood pressure: Vascular function}

\section{Introduction}

Milk is a complex physiological liquid that represents an important source of many potentially bioactive components such as hormones, immunoglobulins, growth factors, carbohydrates and high-quality proteins ${ }^{(1)}$. In the last two decades, there has been an interest in the beneficial effects of milk proteins on human health as a potential ingredient of functional foods aimed at controlling elevated blood pressure (BP) and improving vascular reactivity. Previous reviews have mainly focused on the effects of the casein-derived lactotripeptides (LTP; valineproline-proline (VPP) and isoleucine-proline-proline (IPP)) on BP (see Boelsma \& Kloek $^{(2)}$ and Geleijnse \& Engberink $^{(3)}$ ); however, to date, there has been no comprehensive review of the clinical trials investigating the impact of the two major intact milk proteins (casein and whey) and their hydrolysates on BP and vascular function. The specific aim of the present paper was to critically review the growing literature on the effects of milk proteins and their peptides on BP and vascular function from human intervention studies.

\section{High blood pressure as an important, modifiable} CVD risk factor

CVD are disorders that affect the heart and blood vessels and are the number one cause of death worldwide. In 2008, CVD were responsible for approximately $17 \cdot 3$ million deaths in the world, which is estimated to increase to 23.6 million by $2030^{(4)}$. In the last two decades in some Western European countries (including the UK and France), death rates from CVD have decreased. This has been ascribed

\footnotetext{
Abbreviations: ABPM, ambulatory blood pressure monitor; ACE, angiotensin I-converting enzyme; AIx, augmentation index; BP, blood pressure; C12 peptide, dodeca peptide; DBP, diastolic blood pressure; IPP, isoleucine-proline-proline; LTP, lactotripeptide; RCT, randomised controlled trial; SBP, systolic blood pressure; VPP, valine-proline-proline; WPC $80,80 \%$ whey protein concentrate; WPI, whey protein isolate.
} 
to a combination of: better health care, higher awareness of risk factors and government policies aimed at improving the lifestyle of the population. However, this is not a consistent finding; in some middle- to low-income European countries (such as Ukraine and Romania), CVD mortality has increased rapidly ${ }^{(5)}$. CVD risk factors can be grouped into two general categories: non-modifiable (for example, sex, age, genetic traits and ethnic origins) and modifiable (for example, hyperlipidaemia, hypertension, lack of exercise, obesity, alcohol and smoking). The latter are related mainly to poor lifestyle and diet ${ }^{(6)}$. High BP is a controllable risk factor, yet it is responsible for $13 \%$ of annual deaths worldwide, and is one of the five leading global risks for mortality ${ }^{(7)}$. Kearney et al. ${ }^{(8)}$ reported that more than one in four adults worldwide had hypertension in 2000 , and it is estimated that this number will increase to approximately $29 \%$ by 2025 . Therefore, it is of paramount importance to address this significant public health burden, as its high prevalence has implications, not only for social and economic welfare, but also for the National Health Service (NHS) in the $\mathrm{UK}^{(5)}$.

\section{A holistic marker of CVD risk: vascular dysfunction}

Vascular dysfunction is now a recognised CVD risk factor that develops due to a number of factors including hypertension. It predicts long-term atherosclerotic disease progression and risk of future cardiovascular events ${ }^{(9)}$. Vascular dysfunction is thought to arise from a combination of abnormalities associated with the vascular system. One of its manifestations is endothelial dysfunction, comprising of disorders such as increased permeability, reduced vasodilation, and activation of thrombotic and inflammatory pathways, which is a pathological condition, and is defined by an imbalance between the production of endothelium-derived relaxants such as NO and prostacyclin and contracting factors such as endothelin- ${ }^{(10)}$. NO is one of the key vasodilators that is responsible for the maintenance of vascular tone and reactivity and has a pivotal role in endothelial function.

Recently, much interest has focused on the early detection and evaluation of endothelial dysfunction. Flow-mediated dilatation, a technique that applies vascular ultrasound to examine the conduit brachial artery, is considered as the 'gold-standard' method for the measurement of vascular reactivity. However, this method is highly operator-dependent, which can result in unacceptably high variability $^{(11)}$. In contrast to flow-mediated dilatation, non-invasive laser Doppler imaging and iontophoresis measure the endothelial function of the microcirculation $^{(12)}$, which is believed to be the initial site for the development of endothelial dysfunction in 'at-risk' populations $^{(13)}$. This technique uses transdermal delivery of endothelium-dependent (acetylcholine) and endotheliumindependent (sodium nitroprusside) vasoactive agents by iontophoresis $^{(14)}$.
Arterial stiffness is also an important risk factor for CVD and an essential determinant of vascular function ${ }^{(15)}$. Furthermore, it is considered to be an independent predictor of cardiovascular mortality and morbidity ${ }^{(16)}$. Hypertension may result in vascular remodelling, which is a structural change in arteries, and is also considered to be an age-related disorder ${ }^{(17)}$. According to Stewart et $a l .{ }^{(18)}$, arterial stiffness is not explained by high BP, and the reduction of $\mathrm{BP}$ may not contribute to improvements. However, it is important to note that any reduction in arterial stiffness would occur over a significant time period, and therefore study of the relationship between hypertension and arterial stiffness would require a longterm trial. Nevertheless, Wilkinson et al. ${ }^{(19)}$ demonstrated a relationship between endothelial dysfunction and arterial stiffness, suggesting that any treatment aiming to improve endothelial dysfunction may also have a beneficial effect on arterial stiffness.

The 'gold-standard' assessment of arterial distensibility and stiffness is the carotid-femoral pulse wave velocity by applanation tonometry ${ }^{(20)}$. The principle of this method is that the higher the velocity of pulse waves between two sites, the stiffer the arteries. This method is simple and non-invasive and has high fidelity. It may also be used to measure endothelial function ${ }^{(21)}$, since arterial compliance (the inverse of arterial stiffness) is partly determined by endothelium-dependent vasodilation ${ }^{(22)}$. The augmentation index (AIx), which is an indirect measure of arterial stiffness, can be calculated as the ratio of the magnitude of the reflected pulse wave to the initial wave ${ }^{(23)}$.

\section{Impact of milk consumption on cardiovascular health}

Milk and dairy products have gained an undeserved and scientifically unfounded reputation in the media for exerting adverse effects on cardiovascular health, primarily because of their high SFA content. The detrimental effect of SFA on CVD risk, mediated to a large extent through elevated serum cholesterol, is well recognised. However, this over-simplified association between milk consumption and CVD development may well be misleading ${ }^{(24)}$. Milk is a complex food and different micronutrients and/or nutrients might counteract the detrimental, cholesterol-raising effects of $\mathrm{SFA}^{(25)}$. Furthermore, emerging epidemiological evidence suggests that there is an inverse association between high milk consumption and incidence of $\mathrm{CVD}^{(26)}$. One of the possible mechanisms whereby milk consumption has beneficial effects on CVD health is its potential to lower BP. Growing evidence from population studies indicates that increased milk consumption can lower BP, especially in individuals with elevated $\mathrm{BP}^{(27,28)}$, and it may result in an improvement in pulse wave velocity and pulse pressure ${ }^{(29)}$.

Milk contains many bioactive components that have been reported to lower $\mathrm{BP}$; these include $\mathrm{Ca}, \mathrm{K}$ and milk proteins and/or their bioactive peptides. Bioactive peptides 
can be released from the intact protein by fermentation with proteolytic starter cultures or hydrolysis by enzymes produced by micro-organisms. Peptides can also be liberated through enzymic hydrolysis during gastrointestinal digestion $^{(30)}$. Bovine milk contains approximately $31-33 \mathrm{~g}$ protein per litre, of which about $80 \%$ is casein and $20 \%$ is whey protein. Bioactive peptides are specific protein fragments that have been shown to influence physiological functions and, ultimately, health ${ }^{(31)}$. The activity of these peptides is based on their inherent amino acid composition and sequence. Milk proteins and peptides are reported to possess a wide range of biological properties, and are therefore potential nutraceutical (health-promoting food) ingredients ${ }^{(32)}$. The health targets of such nutraceuticals include cardiovascular health, bone health, weight management, immune defence, and digestive and dental health ${ }^{(30)}$. Milk peptides may exert their effects on cardiovascular health through angiotensin I-converting enzyme (ACE) inhibition, antioxidant activity and opioid actions ${ }^{(30)}$, which will be discussed in detail below.

\section{Evidence from human interventional trials on the antihypertensive effects of milk proteins}

A comprehensive literature search was performed using the electronic databases MEDLINE, the Cochrane Library, EMBASE and Web of Science using the following terms: intervention, randomised controlled trials (RCT), clinical trials, high blood pressure, hypertension, anti-hypert*, vascular function, endothelial function, vascular stiffness, milk protein, milk peptide*, casein, hydrolysate, fermented, sour, humans. Furthermore, hand-searching was performed on the reference lists of both eligible studies and review articles. In addition, Google and Google Scholar were used to confirm that the search was complete. The search period covered studies published in any language until December 2012. The criteria for including studies in the review were: randomised, placebo-controlled trials that examined the effects of milk proteins or peptides on $\mathrm{BP}$ and vascular function in men and women aged 18 years or above, with BP and arterial reactivity/stiffness as outcome measures. The intervention products had to contain milk proteins and/or peptides, and be orally administered (at any dose or frequency).

\section{Effects of casein and casein-derived peptides on blood pressure}

In the last two decades there has been a growing research focus on the evaluation of the antihypertensive effects of milk proteins and their associated peptides in human subjects. In 1995 Japanese researchers identified two casein-derived LTP that exerted ACE-inhibitory effects and these tripeptides quickly became the most extensively studied milk peptides in relation to their hypotensive actions in animals and humans ${ }^{(33)}$. Recently, we have reviewed and performed a meta-analysis on the effects of LTP on BP and observed a significant reduction in both systolic BP (SBP) and diastolic BP (DBP) ${ }^{(34)}$. Therefore these human intervention trials that aimed to evaluate the effects of LTP lie beyond the scope of the present review.

Two human intervention trials have investigated the effects of intact casein on BP (in both acute and chronic settings), which will be discussed within the context of the evidence for whey protein ${ }^{(35,36)}$. Although a great number of ACE-inhibitory peptides have been isolated from casein, only three (VPP and IPP, serine-lysinevaline-tyrosine-proline (SKVYP), dodeca (C12) peptides) have been investigated in human subjects (Table 1). Ashar \& Chand $^{(37)}$ undertook a clinical trial to evaluate the antihypertensive effect of a fermented milk, Dahi, containing SKVYP (ACE-inhibitory peptide) prepared by selected lactic acid cultures. In this study, a total of twenty-nine hypertensive subjects were split into three age groups (group 1, 35-45 years; group 2, 45-55 years; group 3, 55-65 years). Only the subjects who consumed the test product showed a statistically significant decline of $8.9 \mathrm{mmHg}(P<0.05)$ in SBP compared with baseline, which decreased further during the 2-week follow-up period $(-11.6 \mathrm{mmHg} ; P<0.05)$. No effect was observed on DBP or in the other groups.

Sekiya et $_{\text {al }}{ }^{(38)}$ and Sugai ${ }^{(39)}$ examined the effects of a C12 peptide (Phe-Phe-Val-Ala-Pro-Phe-Pro-Glu-Val-Phe-Gly-Lys), as prepared from the hydrolysis of casein with trypsin ${ }^{(38-40)}$, on BP. Sekiya et al. ${ }^{(38)}$ separated the study subjects into three groups: four normotensive ( $60 \mathrm{~g}$ tryptic hydrolysate), four mildly hypertensive (30g tryptic hydrolysate) and eighteen mildly hypertensive subjects ( $10 \mathrm{~g}$ of tryptic hydrolysate twice per d), respectively, and all subjects consumed the supplements for 4 weeks. Unlike the study of Sekiya et $a{ }^{(38)}$, Sugai ${ }^{(39)}$ conducted a study on eighteen mildly hypertensive participants, who consumed $200 \mathrm{~g} \mathrm{C} 12$ peptide for 4 weeks. Both studies reported a fall in BP compared with baseline; Sekiya et al. $^{\left({ }^{38)}\right.}$ reported a significant decrease in BP ( $4.6 \mathrm{mmHg}$ SBP, $6.6 \mathrm{mmHg}$ DBP) in the mildly hypertensive group consuming the $10 \mathrm{~g}$ of hydrolysate twice per $\mathrm{d}$ $(P<0 \cdot 01)$, and Sugai ${ }^{(39)}$ showed a significant fall in DBP (approximately $5 \mathrm{mmHg} ; P<0.001$ ). This stimulated the launch of a soft drink containing the bioactive peptide called Casein DP Peptio Drink (Canebo Co. Ltd) in Japan. Two subsequent clinical trials evaluated the hypotensive effects of the same casein hydrolysate, with the commercial name C12 Peption (DMV International) in Europe ${ }^{(37,41)}$. Townsend et al. ${ }^{(41)}$ performed an acute, randomised, single-blind, cross-over pilot study in ten hypertensive participants who were assigned randomly to one of the five treatment regimens (100 mg C12; $200 \mathrm{mg} \mathrm{C12;} 50 \mathrm{mg}$ $\mathrm{C} 12+877 \mathrm{mg}$ alginic acid; $100 \mathrm{mg} \mathrm{C} 12+1754 \mathrm{mg}$ alginic acid; placebo). Significant reductions in BP were only seen in the group consuming the high dose of C12 (100 mg) combined with alginic acid (1754 mg): $-9.2 \mathrm{mmHg}$ in SBP $6 \mathrm{~h}$ after oral administration compared with $2 \mathrm{~h}$ after 
Table 1. Human studies investigating the association between casein-derived peptides and blood pressure (BP)

\begin{tabular}{|c|c|c|c|c|c|c|}
\hline Reference & $\begin{array}{l}n \text {, sex, subject group, average BP, } \\
\text { age and BMI }\end{array}$ & $\begin{array}{l}\text { Study design } \\
\text { and duration }\end{array}$ & Treatment (per d) & BP measure & $\begin{array}{l}\text { Significant BP change } \\
\text { in treatment group* }\end{array}$ & $\begin{array}{l}\text { Other significant } \\
\text { outcomes }\end{array}$ \\
\hline Sugai $(1998)^{(39)}$ & 18, NR, mild hypertensive, NR & NR, 4 weeks & 200 mg C12 peptide & Office & $\begin{array}{l}\text { In mild hypertensives: } \\
\downarrow \text { SBP by about } 6 \mathrm{mmHg} \\
(P=0.005) \dagger, \\
\text { in normotensives: } \mathrm{NS}\end{array}$ & None \\
\hline $\begin{array}{l}\text { Sekiya } \\
\quad \text { et al. }(1992)^{(38)}\end{array}$ & $\begin{array}{l}\text { Group 1: } 4 \text {, normotensive, NR } \\
\text { Group 2: } 4 \text {, mild hypertensive, NR } \\
\text { Group 3: } 18, \text { mild hypertensive, NR }\end{array}$ & NR, 4 weeks & $\begin{array}{l}20 \mathrm{~g}+40 \mathrm{~g} \text { C12 peptide } \\
10 \mathrm{~g}+20 \mathrm{~g} \text { C12 peptide } \\
2 \times 10 \mathrm{~g} \mathrm{C12} \text { peptide }\end{array}$ & NR & $\begin{array}{l}\text { NS } \\
\text { NS } \\
\downarrow \text { SBP by } 4.6 \mathrm{mmHg}(P<0.01) \dagger, \\
\quad \downarrow \text { DBP by } 6.6 \mathrm{mmHg}(P<0.01) \dagger\end{array}$ & None \\
\hline $\begin{array}{l}\text { Ashar \& } \\
\quad \text { Chand }(2004)^{(37)}\end{array}$ & $\begin{array}{l}\text { Group 1: } 5, \mathrm{NR} \text {, hypertensive, } \\
\text { 147/93.5 mmHg, } 35-45 \text { years, NR } \\
\text { Group 2: } 14, \mathrm{NR} \text {, hypertensive, } \\
\text { 151.5/98.3 mmHg, } 45-55 \text { years, NR } \\
\text { Group 3: } 10, \mathrm{NR} \text {, hypertensive, } \\
\text { 147.9/94.3 mmHg, } 55-65 \text { years, NR }\end{array}$ & $\begin{array}{l}\text { R, NR, C, PAL, } \\
\quad 4 \text { weeks }\end{array}$ & $\begin{array}{l}\text { Amount NR, SKVYP } \\
\text { (Lactobacillus } \\
\text { delbrueckii } \\
\text { ssp. bulgaricus, } \\
\text { Streptococcus } \\
\text { salivarius ssp. } \\
\text { thermophilus, } \\
\text { Lactococcus lactis } \\
\text { biovar. diacetylactis) } \\
\text { (1 } 1 \times 100 \mathrm{ml} \text { Dahi) }\end{array}$ & Office & $\begin{array}{l}\text { NS } \\
\downarrow \text { SBP by } 8.9(\text { SD } 3.4) \mathrm{mmHg} \\
(P<0.05) \dagger \\
\text { NS }\end{array}$ & $\begin{array}{l}\downarrow \text { Serum } \\
\text { cholesterol } \\
\text { by } 37 \cdot 8 \text { (SD 15.9) } \\
\mathrm{mg} / \mathrm{dl} \text { in all test } \\
\text { groups } \\
(P \text { value NR) } \dagger\end{array}$ \\
\hline $\begin{array}{l}\text { Townsend } \\
\text { et al. }(2004)^{(41)}\end{array}$ & $\begin{array}{l}\text { 10, NR, hypertensive, } 152 / 98 \mathrm{mmHg} \text {, } \\
50 \text { years, } 28.7 \mathrm{~kg} / \mathrm{m}^{2}\end{array}$ & $\begin{array}{l}\text { S and D, C, CO, } \\
5 \text { weeks, } \\
\text { acute (different } \\
\text { interventions } \\
\text { each week } \\
\text { separated by } \\
\text { placebo weeks) }\end{array}$ & $\begin{array}{l}100 \mathrm{mg} \mathrm{C12} \text { peptide } \\
(2 \times 3 \text { peptide tablets } \\
+3 \text { placebo tablets }) \\
200 \mathrm{mg} \mathrm{C} 12 \text { peptide } \\
(2 \times 6 \text { peptide tablets }) \\
50 \mathrm{mg} \mathrm{C12} \text { peptide }+877 \mathrm{mg} \\
\text { alginic acid }(2 \times 3 \text { peptide } \\
\text { and alginic acid tablets } \\
+3 \text { placebo tablets }) \\
100 \mathrm{mg} \mathrm{C12} \mathrm{peptide} \\
+1754 \mathrm{mg} \text { alginic acid } \\
(2 \times 6 \text { peptide and } \\
\text { alginic acid tablets })\end{array}$ & $\begin{array}{l}\text { Average } \\
\text { BP at } 2 \mathrm{~h}, \\
6 \mathrm{~h} ; \mathrm{ABPM}\end{array}$ & $\begin{array}{l}\downarrow \text { SBP: } 9.2(\mathrm{SD} 10.1) \mathrm{mmHg}(P=0.02), \\
\downarrow \text { DBP: } 6.0(\mathrm{SD} 6.3) \mathrm{mmHg}(P=0.015), \\
\text { average reductions at } \\
\text { hour } 6 \text { compared with hour } 2\end{array}$ & None \\
\hline $\begin{array}{l}\text { Cadée } \\
\quad \text { et al. }(2007)^{(42)}\end{array}$ & $\begin{array}{l}\text { 48, } 10 \mathrm{M} / 38 \mathrm{~F} \text {, pre-hypertensive, } \\
\text { NR, } 55.6 \text { years, } 25.0 \mathrm{~kg} / \mathrm{m}^{2}\end{array}$ & $\begin{array}{l}\mathrm{R}, \mathrm{D}, \mathrm{C}, \mathrm{PAL} \\
\quad 4 \text { weeks }\end{array}$ & $\begin{array}{l}\text { 3.8 } \mathrm{g} \mathrm{C12} \text { peptide } \\
(2 \times 3 \text { tablets })\end{array}$ & Office & $\begin{array}{l}\downarrow \text { SBP by } 10.7(\text { SD } 7.8) \mathrm{mmHg} \\
(P<0.05) \dagger, \downarrow \mathrm{DBP} \text { by } \\
6.9(\mathrm{SD} 5.9) \mathrm{mmHg}(P<0.05) \dagger\end{array}$ & $\begin{array}{l}\downarrow \text { Angiotensin II } \\
\text { and aldosterone } \\
(P<0.05) \dagger \\
(P<0.05) \ddagger\end{array}$ \\
\hline
\end{tabular}

NR, not reported; C12 peptide, dodeca peptide; $\downarrow$, decrease; SBP, systolic blood pressure; DBP, diastolic blood pressure; R, randomised; C, controlled; PAL, parallel; SKVYPT, serine-lysine-valine-tyrosine-proline; S, single-blind; $\mathrm{D}$, double-blind; CO, cross-over; ABPM, $24 \mathrm{~h}$ ambulatory blood pressure monitor; M, male; F, female. * Mean and standard deviation.

† Compared with baseline.

$\ddagger$ Compared with placebo group at the end of intervention. 
ingestion $(P=0.02)$, and $-6.0 \mathrm{mmHg}$ in DBP $6 \mathrm{~h}$ after oral administration compared with $2 \mathrm{~h} \quad(P=0 \cdot 015)$. Cadée et $a l .{ }^{(42)}$ studied the effects of a daily intake of $3.8 \mathrm{~g} \mathrm{C12}$ peptide in forty-eight Taiwanese subjects. After 4 weeks, SBP and DBP were reduced by $10.7 \mathrm{mmHg}(P<0.05)$ and $6.9 \mathrm{mmHg}(P<0.05)$, respectively, compared with baseline.

It is of note that the trials of Sugai ${ }^{(39)}$, Sekyia et al. ${ }^{(38)}$, Ashar \& Chand ${ }^{(37)}$ and Townsend et al. ${ }^{(41)}$ were in small groups and may have been underpowered. Their subjects were unevenly and, in most cases, not randomly assigned to the treatment groups. Moreover, Sekyia et al. ${ }^{(38)}$ and Sugai ${ }^{(39)}$ did not use control groups. Double-blinding was reported only by Cadée et $a .^{(42)}$ and Townsend et $a l .{ }^{(41)}$. Taken together, the five trials appear to have a high risk of bias, which weakens the strength of evidence supporting their conclusions.

\section{Effects of whey and whey-derived peptides on blood pressure}

A limited number of human trials have examined the hypotensive effects of whey protein and its peptides. The results of clinical trials on the effects of whey and associated peptides on BP are shown in Table 2. To date, Pal \& Ellis $^{(35)}$ are the only research group to compare the effects of the two main intact milk proteins, whey protein (whey protein isolate (WPI), which is the purest intact whey protein obtained from milk, containing about 90-95 g/100 g protein) and casein (sodium caseinate, $90 \mathrm{~g} / 100 \mathrm{~g}$ protein) on $\mathrm{BP}$ in human subjects. A total of seventy normotensive, overweight subjects were assigned to consume $2 \times 27 \mathrm{~g} / \mathrm{d}$ of either WPI, sodium caseinate or glucose (as a control product) for 12 weeks. Significant reductions in DBP were reported in those who ingested both the whey and casein relative to the control group. Furthermore, whey and casein appeared to be equivalent in their BP-lowering capacity. In 2011, the same research group conducted an acute study $^{(36)}$ that compared and evaluated the postprandial effects $(6 \mathrm{~h}$ ) of $45 \mathrm{~g}$ WPI with $45 \mathrm{~g}$ casein on BP in twenty overweight, postmenopausal women. However, in this case, the proteins had no significant effects on BP. Another study investigated the long-term effects of a protein (30 g WPI/d)-enriched diet, in a 2-year randomised, double-blind, placebo-controlled, parallel trial involving 219 women (between $80-90$ years of age) ${ }^{(43)}$. The protein powder was reconstituted with $250 \mathrm{ml}$ water and was consumed daily. Half of the participants in both the treatment and placebo group were taking antihypertensive medication, which did not change over the intervention. While compliance in the treatment group was $88 \%$ by the end of the second year, no significant differences in $\mathrm{BP}$ were reported between groups at the end of year 1 and year 2 .

Kawase et al. ${ }^{(44)}$ conducted a single-blind, randomised trial, in which twenty normotensive men were randomised to fermented milk, supplemented with $80 \%$ whey protein concentrate (approximately $8.8 \mathrm{~g} / \mathrm{d}$; WPC80) for 8 weeks. In addition to an improvement in serum lipids, they reported a significant decrease in SBP in the test group (approximately $6 \mathrm{mmHg} ; P<0.05$ ) compared with the baseline. Interestingly, DBP was not reported in the paper. It is of note that both the test and placebo products contained $0.3 \mathrm{~g}$ soyabean peptides $/ 100 \mathrm{~g}$; and the placebo product contained $2 \mathrm{~g} \mathrm{Na} / 100 \mathrm{~g}$, while the test product did not. In a study by Fluegel et al. ${ }^{(45)}$ normotensive, pre-hypertensive and stage I hypertensive subjects were randomly assigned to consume $28 \mathrm{~g} / \mathrm{d}$ of either hydrolysed or unhydrolysed WPC80 (as the control product) for 6 weeks. At data analysis, volunteers were stratified according to their baseline BP. Although stage I hypertensives showed a significant reduction in SBP $(8 \mathrm{mmHg}$; $P<0.001)$ and DBP $(8.8 \mathrm{mmHg} ; P<0.001)$ compared with baseline; in pre-hypertensives only DBP $(3.8 \mathrm{mmHg}$; $P<0.04)$ appeared to decrease significantly. No effect was seen on the BP of normotensives, and it is of note that there were no reports of comparisons with the placebo group.

Lee et $a l .{ }^{(46)}$ evaluated the effects of acid-reduced mineral whey powder on fifty-three hypertensive volunteers (48\% on antihypertensive medication), who consumed $125 \mathrm{ml}$ of a milk drink daily for 12 weeks. Surprisingly, although there were no significant effects on BP in the test group, a significant reduction in BP was observed in the placebo group. When an ambulatory blood pressure monitor (ABPM) was used, no statistically significant effect was reported in either group.

In all six reviewed trials, subjects were randomly allocated to test and placebo products. However, the random sequence generation was only reported by Hodgson et $a l^{(43)}$. Also, only Lee et $a{ }^{(46)}$ and Hodgson et $a l^{(43)}$ used double-blinding, whereas Fluegel et al. ${ }^{(45)}$ and Pal \& Ellis ${ }^{(36)}$ failed to report the type of blinding, whilst others used single-blinding. Hodgson et al. ${ }^{(43)}$ and $\mathrm{Pal} \&$ Ellis ${ }^{(35)}$ stated that investigators were also blinded to the outcome assessment. Taken together, the six RCT on whey protein and its peptides appear to be of higher quality than the trials on casein-derived peptides.

\section{Evidence from human interventional trials on} the effects of milk proteins on vascular function

More recently, research focus has shifted from measuring the effects of milk proteins on BP to effects on vascular function. We identified thirteen randomised, placebocontrolled human trials, of which nine ${ }^{(47-55)}$ examined the results of the consumption of casein-derived tripeptides (VPP, IPP) in different forms (for example, milk drink, spread, powder); whilst two of these studies investigated the effects of intact whey $\operatorname{protein}^{(35,36)}$, another two used whey-derived peptide (NOP-47) ${ }^{(56,57)}$. The details of these human trials are shown in Table 3. 
Table 2. Randomised controlled trials investigating the association between whey protein and blood pressure (BP)

\begin{tabular}{|c|c|c|c|c|c|c|}
\hline Reference & $\begin{array}{l}n, \text { sex, subject } \\
\text { group, average } \\
\text { BP, age and BMI }\end{array}$ & $\begin{array}{l}\text { Study design } \\
\text { and duration }\end{array}$ & $\begin{array}{l}\text { Treatment } \\
\text { (per d) }\end{array}$ & BP measure & $\begin{array}{l}\text { Significant BP change } \\
\text { in treatment group* }\end{array}$ & $\begin{array}{l}\text { Other significant } \\
\text { outcomes }\end{array}$ \\
\hline $\begin{array}{l}\text { Kawase et al. } \\
{(1999)^{(44)}}^{(40)}\end{array}$ & $\begin{array}{l}20 \mathrm{M} \text {, normotensive with } \\
\text { high cholesterol level, NR, } \\
40.1 \text { years, NR }\end{array}$ & $\begin{array}{l}\mathrm{R}, \mathrm{S}, \mathrm{C}, \mathrm{PAL}, 8 \\
\text { weeks }\end{array}$ & $\begin{array}{l}\text { About } 8.8 \mathrm{~g} \text { WPC } 80 \\
(2 \times 200 \mathrm{ml} \text { fermented } \\
\text { milk })\end{array}$ & $\begin{array}{l}\text { Office, only SBP } \\
\text { reported }\end{array}$ & $\begin{array}{l}\downarrow \text { SBP by about } 6 \mathrm{mmHg} \\
(P<0.05) \dagger\end{array}$ & $\begin{array}{l}\uparrow \text { HDL-C by } 11 \% \\
(P<0.01) \dagger \text { and } \downarrow \\
\text { atherogenic index by } 17 \% \\
(P<0.05) \dagger \text { in treatment } \\
\text { group }\end{array}$ \\
\hline $\begin{array}{l}\text { Lee et al. } \\
\qquad(2007)^{(46)}\end{array}$ & $\begin{array}{c}\text { 53, } 30 \mathrm{M} / 23 \mathrm{~F} \text {, hypertensive } \\
\text { (48\% on AH medication), } \\
142 \cdot 4 / 90.7 \mathrm{mmHg}, 51 \cdot 6 \\
\text { years, } 27.9 \mathrm{~kg} / \mathrm{m}^{2}\end{array}$ & $\begin{array}{l}\mathrm{R}, \mathrm{D}, \mathrm{C}, \mathrm{PAL}, 12 \\
\text { weeks }\end{array}$ & $\begin{array}{l}\text { About } 3 \cdot 25 \mathrm{~g} \text { acid- } \\
\text { reduced mineral- } \\
\text { whey powder } \\
(1 \times 125 \mathrm{ml} \text { milk drink })\end{array}$ & $\begin{array}{l}\text { Office } \\
\text { ABPM }\end{array}$ & $\begin{array}{l}\text { NS } \\
\text { NS }\end{array}$ & None \\
\hline $\begin{array}{l}\text { Fluegel et al. } \\
\qquad(2010)^{(45)}\end{array}$ & $\begin{array}{l}71,57 \mathrm{M} / 14 \mathrm{~F}, \text { normo-, pre- } \\
\text { and hypertensive, } \\
123 \cdot 1 / 74.9 \mathrm{mmHg}, 20 \cdot 6 \\
\text { years, } 24.7 \mathrm{~kg} / \mathrm{m}^{2}\end{array}$ & $\begin{array}{l}\mathrm{R}, \mathrm{NR}, \mathrm{C}, \mathrm{PAL}, 6 \\
\text { weeks }\end{array}$ & $\begin{array}{l}28 \mathrm{~g} \text { hydrolysed WPC } 80 \\
(1 \times \text { about } 300 \mathrm{ml} \\
\text { protein drink })\end{array}$ & Office & $\begin{array}{l}\text { NS } \\
\text { Stratification of results according to } \\
\text { BP classification: } \\
\text { Elevated SBP and DBP }(n 16) \text { : } \\
\downarrow \text { SBP by } 8.0 \mathrm{mmHg} \\
(P \leq 0.001) \dagger, \downarrow \mathrm{DBP} \text { by } \\
8.6 \mathrm{mmHg}(P \leq 0.001) \dagger \\
\text { Elevated SBP and normal DBP } \\
(n 24): \\
\downarrow \text { SBP by } 3.8 \mathrm{mmHg} \\
(P \leq 0.04) \dagger \\
\text { Normotensives }(n 24): \mathrm{NS}\end{array}$ & None \\
\hline $\begin{array}{l}\text { Pal \& Ellis } \\
\quad(2010)^{(35)}\end{array}$ & $\begin{array}{l}70,60 \mathrm{M} / 10 \mathrm{~F}, \text { normoten- } \\
\text { sive, } 117.4 / 65 \cdot 6 \mathrm{mmHg} \\
48.3 \text { years, } 31.3 \mathrm{~kg} / \mathrm{m}^{2}\end{array}$ & $\begin{array}{l}\mathrm{R}, \mathrm{S}, \mathrm{C}, \mathrm{PAL}, 12 \\
\text { weeks }\end{array}$ & $\begin{array}{l}54 \mathrm{~g} \text { WPI90 }(2 \times 250 \mathrm{ml} \\
\text { water }) \\
\\
27 \mathrm{~g} \text { sodium caseinate } \\
(2 \times 250 \mathrm{ml} \text { water })\end{array}$ & Office & $\begin{array}{l}\downarrow \text { SBP by } 3.8 \mathrm{mmHg}(P=0.020) \dagger, \\
\downarrow \text { DBP by } 2.1 \mathrm{mmHg} \\
(P=0.038) \dagger, \downarrow \mathrm{DBP}(P=0.025) \ddagger \\
\downarrow \text { SBP by } 4.9 \mathrm{mmHg}(P=0.017) \dagger, \\
\downarrow \text { DBP } 2.0 \mathrm{mmHg}(P=0.042) \dagger, \downarrow \\
\text { DBP }(P=0.038) \ddagger\end{array}$ & \\
\hline $\begin{array}{l}\text { Pal \& Ellis } \\
\quad(2011)^{(36)}\end{array}$ & $\begin{array}{l}20 \mathrm{~F}, \text { normotensive, } \\
117.7 / 67.7 \mathrm{mmHg}, 57.5 \\
\text { years, } 32.5 \mathrm{~kg} / \mathrm{m}^{2}\end{array}$ & $\begin{array}{l}\text { R, NR, C, CO, } \\
\text { acute, } 4 \text { weeks } \\
\quad+1 \text { week WO }\end{array}$ & $\begin{array}{l}45 \mathrm{~g} \text { WPI90 with a } \\
\text { breakfast } \\
45 \mathrm{~g} \text { sodium caseinate } \\
\text { with a breakfast }\end{array}$ & Office & $\begin{array}{l}\text { NS } \\
\text { NS }\end{array}$ & None \\
\hline $\begin{array}{l}\text { Hodgson et al. } \\
\qquad(2012)^{(43)}\end{array}$ & $\begin{array}{c}119 \mathrm{~F} \text {, hypertensive }(51 \% \\
\text { on AH medication), } \\
142 \cdot 9 / 69 \cdot 9 \mathrm{mmHg}, 74 \cdot 3 \\
\text { years, } 26 \cdot 8 \mathrm{~kg} / \mathrm{m}^{2}\end{array}$ & $\begin{array}{l}\mathrm{R}, \mathrm{D}, \mathrm{PAL}, 2 \\
\text { years }\end{array}$ & $\begin{array}{l}30 \mathrm{~g} / \mathrm{d} \text { WPI90 } \\
(1 \times 250 \mathrm{ml} \text { milk drink })\end{array}$ & Office & $\begin{array}{l}\downarrow \text { SBP by } 0.3(\mathrm{SD} 20.3) \mathrm{mmHg} \\
(P=0.86) \ddagger, \downarrow \mathrm{SBP} \text { by } 0.7 \\
(\mathrm{SD} 14.5) \mathrm{mmHg}(P=0.50) \ddagger\end{array}$ & None \\
\hline
\end{tabular}

M, male; NR, not reported; R, randomised; S, single-blind; C, controlled; PAL, parallel; WPC80, 80\% whey protein concentrate; $\downarrow$, decrease; SBP, systolic blood pressure; HDL-C, HDL-cholesterol; $\uparrow$, increase; F, female; AH, antihypertensive; D, double-blind; ABPM, $24 \mathrm{~h}$ ambulatory blood pressure monitor; DBP, diastolic blood pressure; WPI90, $90 \%$ whey protein isolate; CO, cross-over; WO, wash-out period. Mean and standard deviation.

$¥$ Compared with placebo group at the end of intervention. 
Table 3. Randomised controlled trials investigating the association between milk proteins and vascular function

\begin{tabular}{|c|c|c|c|c|c|c|c|}
\hline Reference & $\begin{array}{l}n \text {, sex, subject group, } \\
\text { average } B P \text {, age and BMI }\end{array}$ & $\begin{array}{l}\text { Study design } \\
\text { and duration }\end{array}$ & Treatment (per d) & $\begin{array}{l}\text { Measure of } \\
\text { vascular } \\
\text { function }\end{array}$ & $\begin{array}{l}\text { Significant effects of treatment } \\
\text { on vascular function* }\end{array}$ & $\begin{array}{l}\text { Simultaneous } \\
\text { BP change?* }\end{array}$ & $\begin{array}{l}\text { Other significant } \\
\text { outcomes }\end{array}$ \\
\hline $\begin{array}{l}\text { Hirota et al. } \\
\qquad(2007)^{(47)}\end{array}$ & $\begin{array}{l}\text { 24, M, mild hypertensive, } \\
144.3 / 86.8 \mathrm{mmHg}, \\
54.1 \text { years, } 23 \cdot 9 \mathrm{~kg} / \mathrm{m}^{2}\end{array}$ & $\begin{array}{l}\mathrm{R}, \mathrm{D}, \mathrm{C}, \mathrm{CO} \\
1+1 \text { weeks }\end{array}$ & $\begin{array}{l}3.87 \mathrm{mg} \text { IPP, } 3.43 \mathrm{mg} \\
\text { VPP }(1 \times 1.25 \mathrm{~g} \\
\text { capsules })\end{array}$ & RH-FBF & $\begin{array}{l}\uparrow \text { Maximum FBF by } 8.5 \mathrm{ml} / \mathrm{min} \text { per } \\
100 \mathrm{ml} \text { tissue }(P<0.001) \dagger \text {, and by } \\
9.2 \mathrm{ml} / \mathrm{min} \text { per } 100 \mathrm{ml} \text { tissue } \\
(P<0.001) \ddagger, \uparrow \text { AUC by } 1.5 \mathrm{ml} / 100 \mathrm{ml} \\
\text { tissue }(P<0.05) \dagger, \downarrow \text { TNF- } \alpha \text { by } \\
0.3 \mathrm{pg} / \mathrm{ml}(P<0.001) \dagger\end{array}$ & $\begin{array}{l}\text { Yes }(\downarrow \text { DBP by } 3.8 \mathrm{mmHg} \text {, } \\
P<0.01 \ddagger)\end{array}$ & $\begin{array}{l}\downarrow \text { Body weight and BMI } \\
\text { in treatment group (by } \\
0.4 \mathrm{~kg}, P<0.01 \dagger ; \text { by } \\
0.1 \mathrm{~kg} / \mathrm{m}^{2}, P<0.01 \dagger \text { ) } \\
\text { and placebo group } \\
\text { (by } 0.4 \mathrm{~kg}, P<0.01 \dagger ; \\
0.2 \mathrm{~kg} / \mathrm{m}^{2}, P<0.01 \dagger \text { ) }\end{array}$ \\
\hline $\begin{array}{l}\text { Jauhiainen et al. } \\
(2007)^{(51)}\end{array}$ & $\begin{array}{c}94,32 \mathrm{M} / 62 \mathrm{~F} \text {, hypertensive, } \\
131.5 / 81.6 \mathrm{mmHg}, \\
52.0 \text { years, } 28.8 \mathrm{~kg} / \mathrm{m}^{2}\end{array}$ & $\begin{array}{l}\text { R, D, C, PAL, } \\
10 \text { weeks }\end{array}$ & $\begin{array}{r}30 \mathrm{mg} \text { IPP, } 22.5 \mathrm{mg} \text { VPP } \\
(2 \times 150 \mathrm{ml} \text { milk drink })\end{array}$ & ABPM & $\begin{array}{l}\downarrow \text { AASI by } 12 \%(-0.043 \text { (SD } 0.13), \\
P=0.043) \dagger\end{array}$ & $\begin{array}{c}\text { Yes }(\downarrow \text { SBP by } 4.1 \text { (SD } 8.4) \\
\text { mmHg, } P<0.001 \ddagger ; \downarrow \\
\text { DBP by } 1.8(\text { SD } 6.5) \\
\text { mmHg, } P=0.048 \ddagger)\end{array}$ & None \\
\hline $\begin{array}{l}\text { Ballard et al. } \\
(2009)^{(56)}\end{array}$ & $\begin{array}{l}20,10 \mathrm{M} / 10 \mathrm{~F}, \text { normotensive, } \\
\mathrm{NR}, 25 \text { years, } 24 \mathrm{~kg} / \mathrm{m}^{2}\end{array}$ & $\begin{array}{l}\text { R, NR, C, CO, } \\
\quad 2+2 \text { weeks } \\
+1 \text { week WO }\end{array}$ & $\begin{array}{l}5 \mathrm{~g} \mathrm{NOP}-47(1 \times 300 \mathrm{ml} \\
\text { water })\end{array}$ & $\begin{array}{l}\text { FMD, } \\
\text { RH-FBF }\end{array}$ & $\begin{array}{l}\uparrow \text { FMD }(8.9 \text { (SD } 3.6) \%, 9.9 \text { (SD } 4.6) \% \\
\text { and } 9.0 \text { (SD } 3.7) \% \text { at } 30,60 \text { and } \\
90 \text { min, } P<0.0001 \text { compared with } \\
\text { corresponding placebo time points), } \\
\uparrow \text { RH-FBF (29.9 (sD 7.8) \%/min at } \\
120 \text { min, } P=0.008 \text { compared with } \\
\text { corresponding placebo time points) }\end{array}$ & - & $\begin{array}{l}\downarrow \mathrm{NO}_{x} \text { (in placebo group } \\
\mathrm{NO}_{x} \text { were lower at } \\
120 \text { min }(P<0.001) \\
\text { compared with } \\
\text { treatment group) }\end{array}$ \\
\hline $\begin{array}{l}\text { Turpeinen et al. } \\
(2009)^{(53)}\end{array}$ & $\begin{array}{l}\text { 62, NR, hypertensive, } \\
138.5 / 86.5 \mathrm{mmHg} \text {, } \\
48 \text { years, } 27.3 \mathrm{~kg} / \mathrm{m}^{2}\end{array}$ & $\begin{array}{l}\text { R, D, C, PAL, } \\
10 \text { weeks }\end{array}$ & $\begin{array}{l}1.8 \mathrm{mg} \text { IPP, } 2.4 \mathrm{mg} \text { VPP } \\
\quad+2 \mathrm{~g} \text { plant sterol } \\
\text { esters }(2 \times 10 \mathrm{~g} \\
\text { vegetable oil-based } \\
\text { low-fat spread })\end{array}$ & PWA, PWV & NS & $\begin{array}{l}\text { Yes }(\downarrow \text { SBP by } 6.0(\text { SD } 19.4) \\
\text { mmHg, } P<0.026 \ddagger)\end{array}$ & $\begin{array}{l}\downarrow \text { TC: } 0.34(\mathrm{SD} 1 \cdot 1) \\
\mathrm{mmol} / /(P=0.003) \ddagger \\
\downarrow \mathrm{LDL}: 0.33(\mathrm{SD} 1 \cdot 0) \\
\mathrm{mmol} / /(P=0.002) \ddagger\end{array}$ \\
\hline \multirow[t]{3}{*}{$\begin{array}{l}\text { Yoshizawa et al. } \\
(2009)^{(49)}\end{array}$} & $\begin{array}{l}\text { 55, F, normotensive, } \\
107.8 / 73.5 \mathrm{mmHg}, \\
57.3 \text { years, } 22.5 \mathrm{~kg} / \mathrm{m}^{2}\end{array}$ & $\begin{array}{l}\mathrm{R}, \mathrm{S}, \mathrm{C}, \mathrm{PAL}, \\
8 \text { weeks }\end{array}$ & $\begin{array}{l}4.3 \mathrm{mg} \text { IPP, } 2.4 \mathrm{mg} \text { VPP } \\
(1 \times 8 \text { tablets })\end{array}$ & $\begin{array}{l}\text { PWV, B-mode } \\
\text { ultrasound }\end{array}$ & $\begin{array}{l}\uparrow \text { Carotid arterial compliance by } \\
0.06 \mathrm{~mm}^{2} / \mathrm{mmHg} \times 10^{-1}(P<0.05) \dagger\end{array}$ & $\begin{array}{l}\text { Yes }(\downarrow \text { SBP by } 6.0 \mathrm{mmHg} \text {, } \\
P<0.05 \dagger)\end{array}$ & None \\
\hline & & & $\begin{array}{l}\text { Exercise }+4.3 \mathrm{mg} \text { IPP, } \\
2.4 \mathrm{mg} \text { VPP }\end{array}$ & & $\begin{array}{l}\uparrow \text { Carotid arterial compliance by } \\
0.14 \mathrm{~mm}^{2} / \mathrm{mmHg} \times 10^{-1}(P<0.01) \dagger, \\
\downarrow \beta \text {-stiffness by } 0.9 \text { units }(P<0.01) \dagger \\
\uparrow \text { arterial distensibility by } \\
0.61 \mathrm{~mm} / \mathrm{mmHg} \times 10^{-3}(P<0.01) \dagger \\
\downarrow \text { incremental elastic modulus by } \\
6.6 \mathrm{mmHg}^{-1} \times 10^{-2}(P<0.01) \dagger\end{array}$ & $\begin{array}{c}\text { Yes }(\downarrow \text { SBP by } 5.0 \mathrm{mmHg}, \\
P<0.05 t, \downarrow \text { DBP by } \\
4.0 \mathrm{mmHg}, P<0.01 \dagger)\end{array}$ & $\begin{array}{l}\downarrow \text { Body mass by } 0.7 \mathrm{~kg} \\
(P<0.05) \dagger ; \uparrow \vee_{O 2 \max } \\
\text { by } 3.1 \mathrm{ml} / \mathrm{kg} \text { per min } \\
(P<0.01) \dagger\end{array}$ \\
\hline & & & Exercise + placebo & & $\begin{array}{l}\uparrow \text { Carotid arterial compliance by } \\
0.08 \mathrm{~mm}^{2} / \mathrm{mmHg} \times 10^{-1}(P<0.05) \dagger \\
\uparrow \text { arterial distensibility by } \\
0.26 \mathrm{~mm} / \mathrm{mmHg} \times 10^{-3}(P<0.01) \dagger\end{array}$ & No & $\begin{array}{l}\downarrow \text { Body mass by } 0.3 \mathrm{~kg} \\
(P<0.05) \dagger ; \uparrow \vee_{O 2 \max } \\
\text { by } 2.6 \mathrm{ml} / \mathrm{kg} \text { per min } \\
(P<0.05) \dagger\end{array}$ \\
\hline \multirow[t]{3}{*}{$\begin{array}{l}\text { Yoshizawa et al. } \\
(2010)^{(48)}\end{array}$} & $\begin{array}{l}\text { 43, F, normotensive, } \\
115 / 68 \mathrm{mmHg}, 57.0 \text { years, } \\
2.72 \mathrm{~kg} / \mathrm{m}^{2}\end{array}$ & $\begin{array}{l}\mathrm{R}, \mathrm{S}, \mathrm{C}, \mathrm{PAL}, \\
8 \text { weeks }\end{array}$ & $\begin{array}{l}4.3 \mathrm{mg} \mathrm{IPP}, 2.4 \mathrm{mg} \text { VPP } \\
\quad(1 \times 8 \text { capsules })\end{array}$ & FMD & $\uparrow \mathrm{FMD}(P<0.05) \dagger$ & $\begin{array}{l}\text { Yes }(\downarrow \text { SBP by } 6.0 \mathrm{mmHg} \text {, } \\
P<0.05 \dagger)\end{array}$ & None \\
\hline & & & $\begin{array}{l}\text { Exercise }+4.3 \mathrm{mg} \text { IPP, } \\
2.4 \mathrm{mg} \text { VPP }\end{array}$ & & $\uparrow \mathrm{FMD}(P<0.01) \dagger$ & $\begin{array}{c}\text { Yes }(\downarrow \text { SBP by } 9.0 \mathrm{mmHg}, \\
P<0.01 \dagger, \downarrow \text { DBP by } \\
5.0 \mathrm{mmHg}, P<0.05 \dagger)\end{array}$ & $\begin{array}{c}\uparrow V_{\text {Oamax }} \text { by } 2.8 \mathrm{~m} / \mathrm{kg} \\
\text { per min }(P<0.01) \dagger\end{array}$ \\
\hline & & & Exercise + placebo & & $\uparrow \mathrm{FMD}(P<0.05) \dagger$ & No & $\begin{array}{c}\uparrow \mathrm{V}_{\mathrm{O} 2 \max } \text { by } 2.5 \mathrm{ml} / \mathrm{kg} \\
\text { per min }(P<0.05) \dagger\end{array}$ \\
\hline \multirow[t]{2}{*}{$\begin{array}{l}\text { Jauhiainen et al. } \\
(2010)^{(50)}\end{array}$} & $\begin{array}{l}89,54 \mathrm{M} / 35 \mathrm{~F} \text {, hypertensive, } \\
153 / 94.7 \mathrm{mmHg}, 49 \text { years, } \\
28.5 \mathrm{~kg} / \mathrm{m}^{2}\end{array}$ & $\begin{array}{l}\mathrm{R}, \mathrm{D}, \mathrm{C}, \mathrm{PAL} \\
12 \text { weeks }\end{array}$ & $\begin{array}{l}11.6 \mathrm{mg} \text { IPP, } 13 \cdot 2 \mathrm{mg} \\
\text { VPP }(1 \times 200 \mathrm{ml} \\
\text { fermented milk })\end{array}$ & $\begin{array}{l}\text { PWA, PWA in } \\
\text { response to } \\
\text { nitroglycerin } \\
\text { and salbutamol }\end{array}$ & NS & No & None \\
\hline & & +12 weeks & $\begin{array}{l}(2 \times 200 \mathrm{ml} \text { fermented } \\
\text { milk })\end{array}$ & & $\downarrow$ Alx by $1.53($ SD 6.8$) \%(P=0.013) \ddagger$ & No & None \\
\hline
\end{tabular}




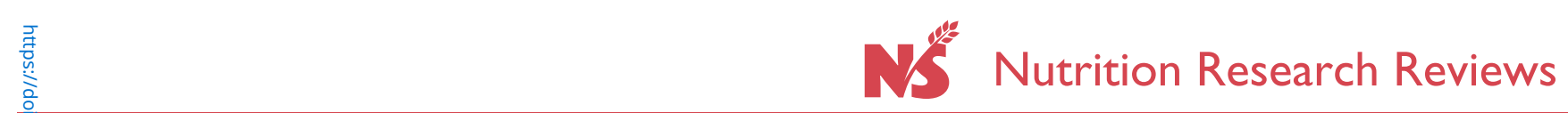

Table 3. Continued

\begin{tabular}{|c|c|c|c|c|c|c|c|}
\hline Reference & $\begin{array}{l}n \text {, sex, subject group, } \\
\text { average BP, age and BMI }\end{array}$ & $\begin{array}{l}\text { Study design } \\
\text { and duration }\end{array}$ & Treatment (per d) & $\begin{array}{l}\text { Measure of } \\
\text { vascular } \\
\text { function }\end{array}$ & $\begin{array}{l}\text { Significant effects of treatment } \\
\text { on vascular function* }\end{array}$ & $\begin{array}{l}\text { Simultaneous } \\
\text { BP change?* }\end{array}$ & $\begin{array}{l}\text { Other significant } \\
\text { outcomes }\end{array}$ \\
\hline \multirow[t]{2}{*}{$\begin{array}{l}\text { Pal \& Ellis } \\
\quad(2010)^{(35)}\end{array}$} & \multirow[t]{2}{*}{$\begin{array}{c}70,60 \mathrm{M} / 10 \mathrm{~F}, \text { normotensive, } \\
117.4 / 65 \cdot 6 \mathrm{mmHg}, 48 \cdot 3 \\
\text { years, } 31.3 \mathrm{~kg} / \mathrm{m}^{2}\end{array}$} & \multirow[t]{2}{*}{$\begin{array}{l}\mathrm{R}, \mathrm{S}, \mathrm{C}, \mathrm{PAL} \\
12 \text { weeks }\end{array}$} & $\begin{array}{l}54 \mathrm{~g} \mathrm{WPI} 90(2 \times 250 \mathrm{ml} \\
\text { water) }\end{array}$ & \multirow[t]{2}{*}{ PWA } & $\begin{array}{l}\downarrow \text { Alx by } 14 \%(P=0.021 \dagger, P=0.006) \ddagger \\
\downarrow \text { Alx }(P=0.006 \text { compared with } \\
\text { casein group })\end{array}$ & $\begin{array}{c}\text { Yes }(\downarrow \text { SBP by } 3.8 \mathrm{mmHg}, \\
P=0.020 \dagger, \uparrow \mathrm{DBP} \text { by } \\
2.1 \mathrm{mmHg}, P=0.038 \dagger \\
\downarrow \mathrm{DBP}, P=0.025 \ddagger)\end{array}$ & None \\
\hline & & & $\begin{array}{l}27 \mathrm{~g} \text { sodium caseinate } \\
(2 \times 250 \mathrm{ml} \text { water })\end{array}$ & & NS & $\begin{array}{c}\text { Yes }(\downarrow \text { SBP by } 4.9 \mathrm{mmHg}, \\
P=0.017 \dagger, \downarrow \text { DBP } \\
2.0 \mathrm{mmHg}, P=0.042 \dagger, \\
\downarrow \text { DBP } P=0.038 \ddagger)\end{array}$ & None \\
\hline \multirow[t]{2}{*}{$\begin{array}{l}\text { Pal \& Ellis } \\
\qquad(2011)^{(36)}\end{array}$} & \multirow{2}{*}{$\begin{array}{l}\text { 20, F, normotensive, } \\
117.7 / 67.7 \mathrm{mmHg} \\
57.5 \text { years, } 32.5 \mathrm{~kg} / \mathrm{m}^{2}\end{array}$} & \multirow{2}{*}{$\begin{array}{l}\mathrm{R}, \mathrm{NR}, \mathrm{C}, \mathrm{CO} \\
\quad \text { acute, } 4 \\
\quad \text { weeks } \\
\quad+1 \text { week WO }\end{array}$} & $\begin{array}{l}45 \mathrm{~g} \text { WPI90 with a } \\
\text { breakfast }\end{array}$ & \multirow[t]{2}{*}{ PWA } & NS & NS & None \\
\hline & & & $\begin{array}{l}45 \mathrm{~g} \text { sodium caseinate } \\
\text { with a breakfast }\end{array}$ & & NS & NS & None \\
\hline $\begin{array}{l}\text { Cicero et al. } \\
\qquad(2011)^{(55)}\end{array}$ & $\begin{array}{l}50,29 \mathrm{M} / 21 \mathrm{~F} \text {, high- } \\
\text { normotensive and mild } \\
\text { hypertensive, } \\
141 \cdot 6 / 86 \cdot 5 \mathrm{mmHg}, \mathrm{NR}, \\
26 \cdot 8 \mathrm{~kg} / \mathrm{m}^{2}\end{array}$ & $\begin{array}{l}\mathrm{R}, \mathrm{D}, \mathrm{C}, \mathrm{PAL} \\
6 \text { weeks }\end{array}$ & $\begin{array}{l}1 \mathrm{mg} \mathrm{IPP}, 2 \mathrm{mg} \text { VPP } \\
\quad(1 \times 250 \mathrm{ml} \text { fruit juice })\end{array}$ & $\begin{array}{l}\text { PWV, impedance } \\
\text { cardiography, } \\
\text { handgrip stres- } \\
\text { sor test }\end{array}$ & $\begin{aligned} & \downarrow \text { PWV by } 0.66 \mathrm{~m} / \mathrm{s}(P=0.001) \dagger, \\
& \downarrow \mathrm{SV} \text { by } 4.8 \mathrm{ml}(P=0.013) \dagger, \\
& \downarrow \text { SI by } 2.1 \mathrm{ml} / \mathrm{m}^{2}(P=0.049) \dagger, \\
& \downarrow \mathrm{ACl} \text { by } 6.7 / 100 \mathrm{~s}^{2}(P=0.044) \dagger, \\
& \downarrow \mathrm{VI} \text { by } 4.3 / 1000 \mathrm{~s}(P=0.048) \dagger\end{aligned}$ & $\begin{array}{l}\text { Yes }(\downarrow \text { SBP by } 4.8 \text { (SD 8.7) } \\
\text { mmHg, } P=0.013 \dagger)\end{array}$ & None \\
\hline $\begin{array}{l}\text { Nakamura et al. } \\
(2011)^{(54)}\end{array}$ & $\begin{array}{l}\text { 70, } 47 \mathrm{M} / 23 \mathrm{~F} \text {, hypertensive, } \\
146 \cdot 9 / 87 \cdot 8 \mathrm{mmHg}, 57 \cdot 8 \\
\text { years, } 23.9 \mathrm{~kg} / \mathrm{m}^{2}\end{array}$ & $\begin{array}{l}\text { R, D, C, PAL, } \\
\quad 8 \text { weeks }\end{array}$ & $\begin{array}{l}1.9 \mathrm{mg} \text { IPP, } 1.5 \mathrm{mg} \text { VPP } \\
\quad(1 \times 4 \text { tablets })\end{array}$ & baPWV & $\begin{array}{l}\downarrow \text { baPWV by } 65.44(\mathrm{sD} 273.1) \mathrm{cm} / \mathrm{s} \\
(P<0.05) \ddagger\end{array}$ & 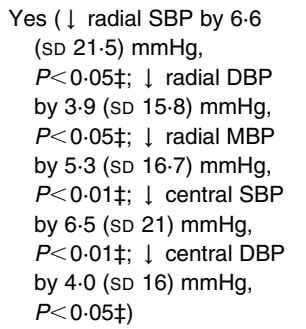 & None \\
\hline $\begin{array}{l}\text { Turpeinen et al. } \\
\qquad(2011)^{(52)}\end{array}$ & $\begin{array}{l}\text { 25, } 15 \mathrm{M} / 10 \mathrm{~F} \text {, mild } \\
\text { hypertensive, } 155 / 90 \mathrm{mmHg} \text {, } \\
52.4 \text { years, } 26.6 \mathrm{~kg} / \mathrm{m}^{2}\end{array}$ & $\begin{array}{l}\mathrm{R}, \mathrm{D}, \mathrm{C}, \mathrm{CO}, \\
\text { acute, } \\
2 \times 1 \mathrm{~d}+2 \\
\text { weeks WO }\end{array}$ & $\begin{array}{l}25 \mathrm{mg} \text { LTP }+2 \mathrm{~g} \text { plant } \\
\text { sterol esters } \\
(1 \times 250 \mathrm{~g} \text { milk drink })\end{array}$ & PWV & NS & $\begin{array}{l}\text { Yes }(\downarrow \text { AUC of SBP by } 2.1 \\
\text { (SD } 5 \cdot 1) \mathrm{mmHg}, P=0.045 \\
\text { and } \downarrow \text { AUC of DBP by } 1.6 \\
\text { (SD } 3.8) \mathrm{mmHg}, P=0.03 \\
\text { at } 480 \mathrm{~min} \text { compared with } \\
\text { PRE) }\end{array}$ & $\begin{array}{l}\uparrow \text { cGMP by } \\
10 \cdot 8 \mathrm{nmol} / \mathrm{mg} \\
\text { creatinine } \\
(P=0.0093) \ddagger\end{array}$ \\
\hline $\begin{array}{l}\text { Ballard et al. } \\
\qquad(2012)^{(57)}\end{array}$ & $\begin{array}{l}\text { 21, } 11 \mathrm{M} / 10 \mathrm{~F} \text {, mild } \\
\text { hypertensive, } 124 / 80 \mathrm{mmHg} \text {, } \\
55 \cdot 2 \text { years, } 27 \cdot 8 \mathrm{~kg} / \mathrm{m}^{2}\end{array}$ & $\begin{array}{l}\mathrm{R}, \mathrm{D}, \mathrm{C}, \mathrm{CO} \\
\text { acute, } 2 \mathrm{~d} \\
\text { with } \\
1 \text { week wo }\end{array}$ & $5 \mathrm{~g} \mathrm{NOP}-47$ (water) & FMD & $\begin{array}{l}\uparrow \mathrm{FMD} \text { by } 4.6(\mathrm{SD} 2.3) \%(P<0.05) \text { at } \\
30 \mathrm{~min} \text { and by } 5.1(\mathrm{SD} 2.3) \% \\
(P<0.05) \text { at } 120 \mathrm{~min} \text { compared with } \\
\text { PRE, and } \uparrow \mathrm{FMD} \text { by } 4.3 \text { (SD } 2.3) \% \text { at } \\
120 \mathrm{~min}(P<0.05 \text { compared with } \\
\text { corresponding placebo time point) }\end{array}$ & - & $\begin{array}{l}1 \text { Serum insulin at } 15, \\
30 \text { and } 60 \text { min } \\
(P<0.001 \text { compared } \\
\text { with corresponding } \\
\text { placebo time point })\end{array}$ \\
\hline
\end{tabular}

BP, blood pressure; M, male; R, randomised; D, double-blind; C, controlled; CO, cross-over; IPP, isoleucine-proline-proline; VPP, valine-proline-proline; RH-FBF, reactive hyperaemia forearm blood flow; $\uparrow$, increase; $\downarrow$, decrease; DBP, diastolic blood pressure; F, female; PAL, parallel; ABPM, $24 \mathrm{~h}$ ambulatory blood pressure monitor; AASI, ambulatory arterial stiffness index; SBP, systolic blood pressure; NR, not reported; WO, wash-out period; FMD, flowstroke volume index; $\mathrm{ACl}$, acceleration index; VI, velocity index; baPWV, brachial-ankle pulse wave velocity; MBP, mean blood pressure; LTP, lactotripeptide; PRE, pre-ingestion; cGMP, cyclin guanosine $3^{\prime}, 5$-monophosphate. * Mean and standard deviation.

†Compared with baseline.

$\ddagger$ Compared with placebo group. 
Hirota et al. ${ }^{(47)}$ investigated the effect of LTP in twenty-four hypertensive men and showed significant improvement in the maximum blood flow during reactive hyperaemia in the treatment group $(+8.5 \mathrm{ml} / \mathrm{min}$ per $100 \mathrm{ml}$ tissue; $P<0.001)$ compared with the placebo group after 1 week of $1.25 \mathrm{~g}$ LTP consumption. Jauhiainen et al. ${ }^{(51)}$ demonstrated a significant improvement in a calculated index of ambulatory arterial stiffness index ( $P=0.043$; compared with baseline) in ninety-four hypertensive subjects after 10 weeks of LTP consumption $(55.5 \mathrm{mg} / \mathrm{d})^{(51)}$. In a later study, the same researchers fed two doses of LTP ( 5 and $50 \mathrm{mg} \mathrm{LTP} / \mathrm{d}$ ) to eighty-nine hypertensive subjects for $12+12$ weeks ${ }^{(50)}$. Although there was a significant reduction in AIx at the end of the high-dose treatment compared with baseline $(-1.53$ (SD 6.8$) \% ; P=0.013$ ), there was no significant change in their index of endothelial function. Turpeinen et $a l .^{(52,53)}$ also failed to report any significant change or differences in arterial stiffness in hypertensive participants in response to the short- and longer-term consumption of a spread containing LTP and plant sterols (short term: $8 \mathrm{~h}$ postprandially, $n 25,250 \mathrm{~g}$ spread per $\mathrm{d}^{(52)}$; long term: 10 weeks, $n$ 62, $20 \mathrm{~g}$ spread per d) ${ }^{(53)}$. Nevertheless, significant decreases in SBP $(P=0.026)$, total serum cholesterol $(P=0.003)$ and LDL $(P=0.002)$ were reported in the longer-term intervention, relative to the control. Nakamura et $a l .{ }^{(54)}$ investigated the effects of LTP $(3.4 \mathrm{mg} / \mathrm{d})$, in the form of tablets, on brachial-ankle pulse wave velocity in seventy subjects with raised BP. They reported a significant reduction in brachial-ankle pulse wave velocity $(65.44$ (SD 273.1$) \mathrm{cm} / \mathrm{s} ; P<0.05)$ compared with the placebo group. Cicero et $a l .{ }^{(55)}$ also reported a significant improvement in pulse wave velocity $(-0.66(\mathrm{SD} \quad 0.81) \mathrm{m} / \mathrm{s}$; $P=0.001$ ), stroke volume, stroke volume index, acceleration index and velocity index after 6 weeks of treatment with LTP $(3 \mathrm{mg} / \mathrm{d})$ in fifty subjects, though these changes were relative to baseline. Yoshizawa et al. ${ }^{(48,49)}$ investigated the combined effect of exercise and LTP consumption on endothelium-dependent dilatation and carotid arterial compliance in postmenopausal women. They found significant improvements in both flow-mediated dilatation and arterial compliance in response to LTP, LTP + exercise, and exercise + placebo groups, but not in the placebo group, and concluded that whilst LTP had a beneficial effect on vascular function, the addition of exercise produced a synergistic effect.

To the best of our knowledge, Pal \& Ellis ${ }^{(35,36)}$ are the only group to date to investigate the effects of the two main intact proteins of milk (casein and whey) on BP and vascular function in postmenopausal, obese women. In a 12-week chronic study, they found that only whey protein lowered the AIx compared with the placebo $(P=0.006)$ and casein $(P=0.006)$ groups $^{(35)}$. In addition, they conducted a postprandial trial measuring not only $\mathrm{BP}$, but also arterial stiffness ${ }^{(36)}$. A breakfast meal in conjunction with one of the three drinks ( $45 \mathrm{~g}$ of whey isolate, sodium caseinate or glucose) was administered to twenty overweight and obese postmenopausal women in a three-way cross-over study design, but could show no effect on vascular function. However, it should be emphasised that during the chronic study, $27 \mathrm{~g}$ of WPI was administered twice per $\mathrm{d}$, whereas in their acute study $45 \mathrm{~g}$ of WPI was given in one dose with a breakfast meal. The different administrative protocols may have affected the physiological effects of the WPI. Ballard et al. ${ }^{(56,57)}$ examined the acute effects of a whey protein hydrolysate (NOP-47) in a preliminary study, which involved young healthy adults $^{(56)}$ and older subjects with confirmed impaired vascular function ${ }^{(57)}$. Significant improvements in endothelium-dependent dilatation were reported in both studies after test product ingestion compared with placebo. However, the acute effect was determined over a period of only $120 \mathrm{~min}$ after a single dose.

Interestingly, Hirota et $a l^{(47)}$ and Jauhiainen et $a l .{ }^{(50)}$ reported improvement in vascular endothelial function and AIx, respectively, after LTP ingestion, but neither could show any effect of LTP on BP. In contrast, significant reductions in BP (either SBP or both SBP and DBP) were reported in the earlier studies of Jauhiainen et al..$^{(51)}$, Cicero et al. ${ }^{(55)}$, Yoshizawa et al. ${ }^{(48,49)}$, Nakamura et al. ${ }^{(54)}$ and Turpeinen et al. ${ }^{(52,53)}$ after feeding LTP, and intact whey and casein proteins ${ }^{(35)}$. However, in a number of these studies ${ }^{(48,49,55)}$, the significant results were expressed relative to baseline only.

Although in all thirteen reviewed RCT, subjects were randomised into test and control groups, only Cicero et al. ${ }^{(55)}$ reported the method of random sequence generation. Likewise, the blinding of the investigator responsible for data analysis was only reported in the chronic study of Pal \& Ellis ${ }^{(35)}$. Blinding of subjects was not stated in the trial of Ballard et al. ${ }^{(56)}$ and Pal \& Ellis ${ }^{(36)}$. Taken together, potential biases in the reviewed trials were moderate, which might influence the strength of the evidence base.

\section{Discussion}

Although an emerging body of evidence supports the beneficial role of the casein-derived LTP consumption in lowering BP, especially in Japanese populations ${ }^{(34)}$, the results of human studies investigating the potential antihypertensive effects of other casein-derived peptides, intact casein and whey and whey-derived peptides seem to be inconsistent, and firm conclusions cannot be drawn. Moreover, whilst there are several RCT involving LTP, the number of human studies that have studied the effects of casein, whey and their peptides are limited.

The degree of heterogeneity in the studies described here has precluded the use of meta-analysis as a means of summating the totality of evidence to link milk proteins with BP. An example of this would be the differing ways in which BP change was reported between studies, as highlighted by Boelsma \& Kloek $^{(2)}$. The change in BP was 
often expressed relative to baseline, rather than to control, which is prone to confounding due to the 'white-coat effect'. This describes a phenomenon in which stress caused by the clinical environment, which may decrease with time as familiarisation with the environment develops, causes a significant impact on BP measures. However, if data are compared with the placebo or control group (which does not contain the tested bioactive component), information on the differential effect of the peptides on $\mathrm{BP}$ can be drawn. Hence, it is of paramount importance to compare results with control rather than baseline values. Furthermore, in order to eliminate or reduce the adverse impact of the 'white-coat effect', a run-in period in which participants take the placebo or visit the clinical unit to familiarise themselves with the measurement techniques can be effectively employed. Only eight of the identified and reviewed studies involved a run-in period $^{(35,36,42,46,50,53-55)}$.

The method of BP measurement might also be a potential confounder. Many factors can contribute to the variability in $\mathrm{BP}$, independently of the intervention, such as the central nervous system ${ }^{(58)}$. Office BP measurements were performed by sphygmomanometer in the majority of studies, with only a few using $24 \mathrm{~h} \mathrm{ABPM}{ }^{(41,46,51)}$. However, there is evidence that $24 \mathrm{~h} \mathrm{ABPM}$ is a better predictor of CVD risk, since it measures BP more accurately, and has been reported to be more reproducible and can help to eliminate the 'white-coat effect' ${ }^{\text {(59) }}$.

It is well known that body weight and BMI have a key role to play in $\mathrm{BP}$ management ${ }^{(60)}$, yet exercise levels and changes in body weight and BMI were rarely reported in the reviewed trials. Only Hirota et $a l .{ }^{(47)}$ reported a significant decrease in BMI and body weight in both test and placebo groups; however, the change seemed to be somewhat smaller in the test group. Fluegel et al. ${ }^{(45)}$, Pal \& Ellis ${ }^{(35,36)}$, Hodgson et al. ${ }^{(43)}$ and Yoshizawa et al. ${ }^{(48,49)}$ stated baseline and end-of-treatment BMI/weight and exercise level data, but, however, failed to report any statistically significant changes.

In most studies the test products were sour or fermented $\operatorname{milk}^{(37,38,39,43,44,46,50-52)}$, tablets or capsules ${ }^{(41,42,47-49,54)}$, fruit juice ${ }^{(55)}$, or spread containing peptides ${ }^{(53)}$. However, Ballard et al. ${ }^{(56,57)}$, Fluegel et al. ${ }^{(45)}$ and Pal \& Ellis ${ }^{(35,36)}$ requested that their subjects consumed the protein hydrolysate and isolate mixed with water. Food vehicles may influence the physiological effects of the bioactive components, as other constituents within the food matrices can exert synergistic or antagonistic effects. Furthermore, additional bioactive peptides may enhance absorption of $\mathrm{Ca}$ and $\mathrm{K}$, which may have independent hypotensive effects $^{(61)}$. The choice of an appropriate control product is of paramount importance in order to evaluate the effect of the active ingredient. While some studies provided detailed information on nutrient composition, and evidence of closely matched test and control products, others revealed differences in both the energy and carbohydrate content between the test and control ${ }^{(50,51,53)}$. In a few cases, a higher $\mathrm{Ca}^{(46,50,51)}$ or $\mathrm{K}^{(50,51)}$ content of the test product could have influenced its BP-lowering effects. The control products in some trials had a higher protein content than treatment products ${ }^{(44,53)}$. Fluegel et al. ${ }^{(45)}$ used unhydrolysed WPC80 as a control as it closly mimicked the distinctive mouth-feel and appearance of the test product (hydrolysed WPC80). In contrast, Pal \& Ellis ${ }^{(35,36)}$ used glucose as the control; this was despite existing evidence to show that sugar consumption has been reported to have detrimental effects on hypertension and gene expression, which may render glucose a less valuable control ${ }^{(62-64)}$.

A growing number of human trials have investigated the impact of milk proteins and peptides on vascular function. The majority of these trials have studied the effects of LTP and only a few have examined the effects of whey, wheyderived peptides and casein-derived peptides other than LTP. In most studies, a range of different methods was used to assess vascular function. While some studies evaluated only one parameter of vascular function ${ }^{(47,51)}$, other trials assessed not only endothelial function and arterial stiffness, but also inflammatory markers ${ }^{(35,36,56,57)}$. Although the results of these human studies suggest some benefit on vascular reactivity after consuming milk protein or peptide, the evidence still has insufficient strength for reliable conclusions and dietary recommendations. Further human trials must assess the impact of milk proteins on a range of measures of vascular function before we can fully understand their potential benefit to cardiovascular health.

\section{Putative mechanisms underlying the impact of milk peptides on hypertension and vascular function}

There is evidence to suggest that the BP-lowering effects of milk-derived proteins and peptides are mediated through the inhibition of ACE (as a direct pathway in BP regulation) or via non-ACE-inhibition routes (as indirect pathways in $\mathrm{BP}$ regulation). The most thoroughly investigated hypotensive mechanism by which milk proteins and their associated peptides may ameliorate $\mathrm{BP}$ is through ACE inhibition. The principle of this mechanism is based on the inhibition of the enzyme ACE, the formation of different vasoconstrictor substances (for example, angiotensin II, endothelin-1) and the reduced degradation and inhibition of vasodilatory compounds (for example, bradykinin). Thus, ACE inhibition can exert a favourable effect not only on BP, but also on vascular function. Studies in vitro with the rat model (for reviews, see Murray \& Fitzgerald $^{(65)}$ and Saito ${ }^{(66)}$ ) observed ACE-inhibitory activity and identified $\mathrm{IC}_{50}$ values (concentrations of peptides that are required to exert $50 \%$ reduction in ACE) of a large number of peptides isolated from the enzymic digest of milk proteins ${ }^{\text {(30) }}$. Whey-derived hydrolysate is reported to exert the highest ACE-inhibitory activity, but 
has failed to show BP-lowering effects in spontaneously hypertensive rats; however, peptides with low ACEinhibitory activity triggered significant BP-lowering ${ }^{(67)}$. Thus, the results of the in vitro or animal studies appear to be inconsistent, supporting other potential mechanisms of action. There has also been inconsistency in the outcomes from human studies.

Sipola et al. ${ }^{(68)}$ demonstrated that the administration of $\alpha$-lactorphin or $\beta$-lactorphin to spontaneously hypertensive rats induced an endothelium-dependent relaxation of mesenteric arteries, which was suppressed by a NO synthase inhibitor. This suggested that NO may be involved in this process, playing an important role in endothelial function and hence in BP regulation. Furthermore, Hirota et $a l .{ }^{(47)}$ found that LTP-induced endothelium-dependent relaxation of isolated aortic rings was suppressed by $\mathrm{NO}$ synthase inhibitors, bradykinin $\mathrm{B} 2$ receptor antagonists and $\mathrm{K}^{+}$channel inhibitors.

Another indirect route to attenuate BP may be through immunomodulatory pathways. Rutherfurd-Marwick \& Moughan ${ }^{(69)}$ suggested that milk-derived peptides may activate the maturation and proliferation of $\mathrm{T}$ cells and natural killer cells, thus playing an important role in immunomodulation ${ }^{(69)}$. According to Meisel $^{(70)}$, the remarkable relationship between the immune system and opioid peptides is supported by the fact that opioid $\mu$ receptors for endorphins can be found on $\mathrm{T}$ lymphocytes and human phagocytic leucocytes.

The inhibition of the sympathetic nervous system through opioid activity might be another potential mechanism of action. In a recent study, Usinger et al. ${ }^{(71)}$ reported a significant decrease in sympathetic activity after consumption of fermented milk for 8 weeks in borderline hypertensive subjects. However, simultaneous BP lowering was not observed in this trial. There is evidence that some milk protein hydrolysates, for instance $\alpha$ - and $\beta$-casomorphins, act as opioid agonists ${ }^{(72)}$, and may exert an analgesic effect on the nervous system ${ }^{(73,74)}$. This is supported by the study of Nurminen et al. ${ }^{(75)}$, in which an opioid receptor antagonist (naloxone) was employed and researchers found an absence of any effect on BP. This suggests that BP lowering was mediated by the opioid receptors. Phosphopeptides of milk proteins may enhance the solubility of different minerals such as $\mathrm{Ca}$, thus improving their absorption in the intestine ${ }^{(61)}$. Although oral supplementation of $\mathrm{Ca}$ has not been shown to decrease hypertension ${ }^{(76)}$, dietary $\mathrm{Ca}$ intake might have a favourable impact on raised $\mathrm{BP}^{(77)}$.

There is growing evidence that oxidative stress and reduced antioxidant status are involved in the pathogenesis of hypertension ${ }^{(78,79)}$. Several studies reported antioxidant effects of both casein and whey hydrolysates produced by different enzymes ${ }^{(80,81)}$. Many tripeptides (other than LTP, for example, Xaa-Xaa-Trp/Tyr, Tyr-His-Tyr) that show high scavenging activity and strong synergistic effects with phenolic antioxidants have been identified in milk ${ }^{(82)}$.
A tripeptide, Xaa-Xaa-Cys $(\mathrm{SH})$, has been shown to possess a high peroxynitrite-scavenging activity ${ }^{(82)}$, which is an important compound in the health of vascular function $^{(83)}$.

\section{Bioavailability}

During gastrointestinal digestion, peptides and amino acids are released from the ingested protein. To be effective in humans, milk peptides, which have been shown to exert beneficial effects on BP and vascular function in vitro and in animal models, must first be absorbed. A peptide is bioavailable if it is resistant to further digestion, stable while being transported across the gut mucosa and intestinal wall, and resistant to serum peptidases in the circulation $^{(84)}$. In addition, the peptide must reach its target site or organ in an active form ${ }^{(84)}$. Evidence supports the idea that short-chain peptides are absorbed intact via different intestinal transporters (for example, carriermediated, paracellular diffusion or specific transporter) and induce systemic effects ${ }^{(85,86)}$. Conversely, Wuerzner et $a l .{ }^{(87)}$ reported that VPP and IPP were poorly absorbed and eliminated from the human body quickly, preventing ACE-inhibitory activity. The phenomenon of effective ACE-inhibitory activity of some peptides in vitro does not always translate into significant effects in animal models or human studies. Discrepancy between the ACE-inhibitory activity of tripeptides in vitro and in vivo experiments may be due to the bioavailability of these peptides. However, there have been several reports of potent ACE-inhibitory activity in peptides produced from the digestion of protein using a combination of enzymes ${ }^{(88-90)}$. Interestingly, Foltz et al. ${ }^{(86)}$ found significant concentrations of IPP in the blood of subjects consuming the placebo product, a WPI, which did not contain this tripeptide. This implies that IPP was produced during digestion. Information on the in vivo kinetics of bioactive peptides derived from milk proteins is very inconsistent, yet an essential factor for understanding the action of milk proteins. More research is required to elucidate their bioavailability in the human body.

\section{Conclusions and future recommendations}

There has been increasing interest in producing functional foods to improve cardiovascular health, as CVD remains one of the major public health burdens. Consumption of milk and dairy products is associated with beneficial cardiovascular effects. One hypothesised mechanism is through the hypotensive effect of milk proteins and peptides. The current available literature provides some evidence for the beneficial effects of milk proteins and peptides on BP and vascular function, but sufficiently powered RCT will be required to substantiate these effects. In contrast to the pharmacological treatment of hypertension, food-derived proteins have not been shown to cause side-effects, 
making them safe to consume by individuals with a variety of other disease conditions.

Robust, well-designed, RCT conducted in 'at-risk' population will be required to confirm the potential beneficial impacts of milk-derived proteins and peptides on BP and vascular function. Future studies should consider investigating both acute and chronic effects of proteins, applying $24 \mathrm{~h} \mathrm{ABPM}$ and more detailed cardiovascular reactivity tests to assess the impacts on both endothelial function and arterial compliance. Comparison of the two major intact milk proteins could provide valuable information on which is the more efficacious in attenuating BP and/or improving vascular function. Existing evidence for the mechanisms by which milk-derived proteins and peptides may make an impact on BP and vascular function is both limited and inconsistent; further study is clearly warranted.

\section{Acknowledgements}

The present review received no specific grant from any funding agency in the public, commercial or not-for-profit sectors. A. A. F. is supported by a UK Biotechnology and Biological Sciences Research Council studentship.

A. A. F. drafted the manuscript. All authors contributed to and approved the final version of the manuscript.

The authors declare no conflicts of interest.

\section{References}

1. Shah N (2000) Effects of milk-derived bioactives: an overview. Br J Nutr 84, 3-10.

2. Boelsma E \& Kloek J (2009) Lactotripeptides and antihypertensive effects: a critical review. BrJ Nutr 101, 776-786.

3. Geleijnse JM \& Engberink MF (2010) Lactopeptides and human blood pressure. Curr Opin Lipidol 21, 58-63.

4. World Health Organization (2011) Cardiovascular diseases (CVDs) Fact sheet no. 317. http://www.who.int/mediacentre/factsheets/fs317/en/index.html (accessed January 2011)

5. British Heart Foundation (2010) Coronary heart disease statistics 2010 http://www.bhf.org.uk/publications/viewpublication. aspx?ps=1001546 (accessed December 2011)

6. Lovegrove J \& Jackson K (2011) Functional foods and coronary heart disease. In Functional Foods: Concept to Product, 2nd ed., pp. 153-201 [M Saarela, editor]. Oxford: Woodhead Publishing Limited.

7. World Health Organization (2009) Global health risk: mortality and burden of disease attributable to selected major risks http://www.who.int/healthinfo/global_burden_disease/ GlobalHealthRisks_report_full.pdf (accessed January 2011)

8. Kearney PM, Whelton M, Reynolds K, et al. (2005) Global burden of hypertension: analysis of worldwide data. Lancet 365, 217-223.

9. Schachinger V, Britten M \& Zeiher A (2000) Prognostic impact of coronary vasodilator dysfunction on adverse long-term outcome of coronary heart disease. Circulation 101, 1899-1906.

10. Verma S \& Anderson TJ (2002) Fundamentals of endothelial function for the clinical cardiologist. Circulation $\mathbf{1 0 5}$, 546-549.

11. Corretti MC, Anderson TJ, Benjamin EJ, et al. (2002) Guidelines for the ultrasound assessment of endothelial-dependent flow-mediated vasodilation of the brachial artery: a report of the International Brachial Artery Reactivity Task Force. $J$ Am Coll Cardiol 39, 257-265.

12. Turner J, Belch JJ \& Khan F (2008) Current concepts in assessment of microvascular endothelial function using laser Doppler imaging and iontophoresis. Trends Cardiovasc Med 18, 109-116.

13. Brodsky SV, Gealekman O, Chen J, et al. (2004) Prevention and reversal of premature endothelial cell senescence and vasculopathy in obesity-induced diabetes by ebselen. Circ Res 94, 377-384.

14. Morris SJ \& Shore AC (1996) Skin blood flow responses to the iontophoresis of acetylcholine and sodium nitroprusside in man: possible mechanisms. J Physiol 496, 531-542.

15. Payne RA \& Webb DJ (2006) Arterial blood pressure and stiffness in hypertension: is arterial structure important? Hypertension 48, 366-367.

16. Boutouyrie P, Tropeano AI, Asmar R, et al. (2002) Aortic stiffness is an independent predictor of primary coronary events in hypertensive patients: a longitudinal study. Hypertension 39, 10-15.

17. Franklin SS (2005) Arterial stiffness and hypertension: a two-way street? Hypertension 45, 349-351.

18. Stewart AD, Jiang B, Millasseau SC, et al. (2006) Acute reduction of blood pressure by nitroglycerin does not normalize large artery stiffness in essential hypertension. Hypertension 48, 404-410.

19. Wilkinson IB, Qasem A, McEniery CM, et al. (2002) Nitric oxide regulates local arterial distensibility in vivo. Circulation 105, 213-217.

20. Rhee M, Lee H \& Park J (2008) Measurements of arterial stiffness: methodological aspects. Korean Circ J 38, 343-350.

21. Swampillai J, Doshi S, Fraser A, et al. (2005) Review: Clinical assessment of endothelial function - an update. Br J Diabetes Vasc Dis 5, 72-76.

22. Kelly RP, Millasseau SC, Ritter JM, et al. (2001) Vasoactive drugs influence aortic augmentation index independently of pulse-wave velocity in healthy men. Hypertension 37, 1429-1433.

23. Whitworth JA (2003) World Health Organization (WHO)/ International Society of Hypertension (ISH) statement on management of hypertension. J Hypertens 21, 1983-1992.

24. Givens DI (2012) Milk in the diet: good or bad for vascular disease? Proc Nutr Soc 71, 98-104.

25. Lorenzen JK \& Astrup A (2011) Dairy calcium intake modifies responsiveness of fat metabolism and blood lipids to a high-fat diet. Br J Nutr, (epublication ahead of print version 31 January 2011).

26. Elwood PC, Pickering JE, Givens DI, et al. (2010) The consumption of milk and dairy foods and the incidence of vascular disease and diabetes: an overview of the evidence. Lipids 45, 925-939.

27. Beydoun MA, Gary TL, Caballero BH, et al. (2008) Ethnic differences in dairy and related nutrient consumption among US adults and their association with obesity, central obesity, and the metabolic syndrome. Am J Clin Nutr 87 , 1914-1925.

28. Engberink MF, Hendriksen MA, Schouten EG, et al. (2009) Inverse association between dairy intake and hypertension: the Rotterdam Study. Am J Clin Nutr 89, 1877-1883.

29. Crichton GE, Elias MF, Dore GA, et al. (2012) Relations between dairy food intake and arterial stiffness: pulse wave velocity and pulse pressure. Hypertension 59, $1044-1051$.

30. Korhonen H \& Pihlanto A (2006) Bioactive peptides: production and functionality. Int Dairy J 16, 945-960. 
31. Kitts DD \& Weiler K (2003) Bioactive proteins and peptides from food sources. Applications of bioprocesses used in isolation and recovery. Curr Pharm Des 9, 1309-1323.

32. Hartmann R \& Meisel H (2007) Food-derived peptides with biological activity: from research to food applications. Curr Opin Biotechnol 18, 163-169.

33. Nakamura Y, Yamamoto N, Sakai K, et al. (1995) Purification and characterization of angiotensin I-converting enzyme inhibitors from sour milk. J Dairy Sci 78, 777-783.

34. Fekete AA, Givens DI \& Lovegrove JA (2013) Effects of caseinderived lactotripeptides on blood pressure: a meta-analysis of randomized controlled trials in humans. J Hypertens, (In the Press).

35. Pal S \& Ellis V (2010) The chronic effects of whey proteins on blood pressure, vascular function, and inflammatory markers in overweight individuals. Obesity 18, 1354-1359.

36. Pal S \& Ellis V (2011) Acute effects of whey protein isolate on blood pressure, vascular function and inflammatory markers in overweight postmenopausal women. Br J Nutr 105, 1512-1519.

37. Ashar MN \& Chand R (2004) Fermented milk containing ACE-inhibitory peptides reduces blood pressure in middle aged hypertensive subjects. Milchwissenschaft 59, 363-366.

38. Sekiya S, Kobayashi Y, Kita E, et al. (1992) Antihypertensive effects of tryptic hydrolysate of casein on normotensive and hypertensive volunteers. J Nutr Food Sci 45, 513-517.

39. Sugai R (1998) ACE inhibitors and functional foods. Bull IDF 336, 17-20.

40. Karaki H, Doi K, Sugano S, et al. (1990) Antihypertensive effect of tryptic hydrolysate of milk casein in spontaneously hypertensive rats. Comp Biochem Physiol C 96, 367-371.

41. Townsend RR, McFadden CB, Ford V, et al. (2004) A randomized, double-blind, placebo-controlled trial of casein protein hydrolysate (C12 peptide) in human essential hypertension. Am J Hypertens 17, 1056-1058.

42. Cadée JA, Chang CY, Chen CW, et al. (2007) Bovine casein hydrolysate (C12 peptide) reduces blood pressure in prehypertensive subjects. Am J Hypertens 20, 1-5.

43. Hodgson JM, Zhu K, Lewis JR, et al. (2012) Long-term effects of a protein-enriched diet on blood pressure in older women. Br J Nutr 107, 1664-1672.

44. Kawase M, Hashimoto H, Hosoda M, et al. (2000) Effect of administration of fermented milk containing whey protein concentrate to rats and healthy men on serum lipids and blood pressure. J Dairy Sci 83, 255-263.

45. Fluegel SM, Shultz TD, Powers JR, et al. (2010) Whey beverages decrease blood pressure in prehypertensive and hypertensive young men and women. Int Dairy $J \mathbf{2 0}$, $753-760$.

46. Lee YM, Skurk T, Hennig M, et al. (2007) Effect of a milk drink supplemented with whey peptides on blood pressure in patients with mild hypertension. Eur J Nutr 46, $21-27$.

47. Hirota T, Ohki K, Kawagishi R, et al. (2007) Casein hydrolysate containing the antihypertensive tripeptides Val-Pro-Pro and Ile-Pro-Pro improves vascular endothelial function independent of blood pressure-lowering effects: contribution of the inhibitory action of angiotensin-converting enzyme. Hypertens Res 30, 489-496.

48. Yoshizawa M, Maeda S, Miyaki A, et al. (2010) Additive beneficial effects of lactotripeptides intake with regular exercise on endothelium-dependent dilatation in postmenopausal women. Am J Hypertens 23, 368-372.

49. Yoshizawa M, Maeda S, Miyaki A, et al. (2009) Additive beneficial effects of lactotripeptides and aerobic exercise on arterial compliance in postmenopausal women. Am J Physiol Heart Circ Physiol 297, H1899-H1903.
50. Jauhiainen T, Ronnback M, Vapaatalo H, et al. (2010) Long-term intervention with Lactobacillus belveticus fermented milk reduces augmentation index in hypertensive subjects. Eur J Clin Nutr 64, 424-431.

51. Jauhiainen T, Ronnback M, Vapaatalo H, et al. (2007) Lactobacillus helveticus fermented milk reduces arterial stiffness in hypertensive subjects. Int Dairy $J \quad \mathbf{1 7}$, 1209-1211.

52. Turpeinen AM, Ehlers PI, Kivimaki AS, et al. (2011) IlePro-Pro and Val-Pro-Pro tripeptide-containing milk product has acute blood pressure lowering effects in mildly hypertensive subjects. Clin Exp Hypertens 33, 388-396.

53. Turpeinen AM, Kumpu M, Ronnback M, et al. (2009) Antihypertensive and cholesterol-lowering effects of a spread containing bioactive peptides IPP and VPP and plant sterols. J Func Food 1, 260-265.

54. Nakamura T, Mizutani J, Ohki K, et al. (2011) Casein hydrolysate containing Val-Pro-Pro and Ile-Pro-Pro improves central blood pressure and arterial stiffness in hypertensive subjects: a randomized, double-blind, placebo-controlled trial. Atherosclerosis 219, 298-303.

55. Cicero AF, Rosticci M, Gerocarni B, et al. (2011) Lactotripeptides effect on office and 24-h ambulatory blood pressure, blood pressure stress response, pulse wave velocity and cardiac output in patients with high-normal blood pressure or first-degree hypertension: a randomized double-blind clinical trial. Hypertens Res 34, 1035-1040.

56. Ballard KD, Bruno RS, Seip RL, et al. (2009) Acute ingestion of a novel whey-derived peptide improves vascular endothelial responses in healthy individuals: a randomized, placebo controlled trial. Nutr J 8, 34 .

57. Ballard KD, Kupchak BR, Volk BM, et al. (2013) Acute effects of ingestion of a novel whey-derived extract on vascular endothelial function in overweight, middle-aged men and women. Br J Nutr 109, 882-893.

58. Mancia G, Ferrari A, Gregorini L, et al. (1983) Blood pressure and heart rate variabilities in normotensive and hypertensive human beings. Circ Res 53, 96-104.

59. Mancia G, De Backer G, Dominiczak A, et al. (2007) 2007 Guidelines for the management of arterial hypertension: The Task Force for the Management of Arterial Hypertension of the European Society of Hypertension (ESH) and of the European Society of Cardiology (ESC). Eur Heart $J$ 28, 1462-1536.

60. Drøyvold WB, Midthjell K, Nilsen TI, et al. (2005) Change in body mass index and its impact on blood pressure: a prospective population study. Int J Obes 29, 650-655.

61. Sato R, Noguchi T \& Naito H (1986) Casein phosphopeptide (CPP) enhances calcium absorption from the ligated segment of rat small intestine. J Nutr Sci Vitaminol 32, 67-76.

62. Chess DJ, Lei B, Hoit BD, et al. (2007) Deleterious effects of sugar and protective effects of starch on cardiac remodeling, contractile dysfunction, and mortality in response to pressure overload. Am J Physiol Heart Circ Physiol 293, $\mathrm{H} 1853-\mathrm{H} 1860$.

63. Dai S \& McNeill JH (1995) Fructose-induced hypertension in rats is concentration- and duration-dependent. J Pharmacol Toxicol Methods 33, 101-107.

64. Sharma N, Okere IC, Barrows BR, et al. (2008) High-sugar diets increase cardiac dysfunction and mortality in hypertension compared to low-carbohydrate or high-starch diets. J Hypertens 26, 1402-1410.

65. Murray BA \& FitzGerald RJ (2007) Angiotensin converting enzyme inhibitory peptides derived from food proteins: biochemistry, bioactivity and production. Curr Pharm Des $\mathbf{1 3}$ $773-791$ 
66. Saito T (2008) Antihypertensive peptides derived from bovine casein and whey proteins. Adv Exp Med Biol 606, 295-317.

67. Costa ED, Gontijo JD \& Netto F (2007) Effect of heat and enzymatic treatment on the antihypertensive activity of whey protein hydrolysates. Int Dairy J 17, 632-640.

68. Sipola M, Finckenberg P, Korpela R, et al. (2002) Effect of long-term intake of milk products on blood pressure in hypertensive rats. J Dairy Res 69, 103-111.

69. Rutherfurd-Markwick KJ \& Moughan PJ (2005) Bioactive peptides derived from food. J AOAC Int $\mathbf{8 8}, 955-966$.

70. Meisel H (1997) Biochemical properties of bioactive peptides derived from milk proteins: Potential nutraceuticals for food and pharmaceutical applications. Livest Prod Sci 50, 125-138.

71. Usinger L, Ibsen H, Linneberg A, et al. (2010) Human in vivo study of the renin-angiotensin-aldosterone system and the sympathetic activity after 8 weeks daily intake of fermented milk. Clin Physiol Funct Imaging 30, 162-168.

72. Loukas S, Varoucha D, Zioudrou C, et al. (1983) Opioid activities and structures of $\alpha$-casein-derived exorphins. Biochemistry 22, 4567-4573.

73. Chang KJ, Cuatrecasas P, Wei ET, et al. (1982) Analgesic activity of intracerebroventricular administration of morphiceptin and $\beta$-casomorphins: correlation with the morphine (micro) receptor binding affinity. Life Sci 30, 1547-1551.

74. Matthies H, Stark H, Hartrodt B, et al. (1984) Derivatives of $\beta$-casomorphins with high analgesic potency. Peptides 5, 463-470.

75. Nurminen ML, Sipola M, Kaarto H, et al. (2000) $\alpha$-Lactorphin lowers blood pressure measured by radiotelemetry in normotensive and spontaneously hypertensive rats. Life Sci 66, 1535-1543.

76. Dickinson HO, Nicolson DJ, Cook JV, et al. (2006) Calcium supplementation for the management of primary hypertension in adults The Cochrane Database of Systematic Reviews 2006, issue 2, CD004639. http://www.mrw. interscience.wiley.com/cochrane/clsysrev/articles/CD004639/ frame.html

77. Hatton DC \& McCarron DA (1994) Dietary calcium and blood pressure in experimental models of hypertension. Hypertension 23, 513-530.

78. de Champlain J, Wu R, Girouard H, et al. (2004) Oxidative stress in hypertension. Clin Exp Hypertens 26, 593-601.
79. Rodrigo R, Prat H, Passalacqua W, et al. (2007) Relationship between oxidative stress and essential hypertension. Hypertens Res 30, 1159-1167.

80. Rival SG, Boeriu CG \& Wichers HJ (2001) Caseins and casein hydrolysates. 2. Antioxidative properties and relevance to lipoxygenase inhibition. J Agric Food Chem 49, 295-302.

81. Hernandez-Ledesma B, Davalos A, Bartolome B, et al. (2005) Preparation of antioxidant enzymatic hydrolysates from $\alpha$-lactalbumin and $\beta$-lactoglobulin. Identification of active peptides by HPLC-MS/MS. J Agric Food Chem 53, 588-593.

82. Pihlanto A (2006) Antioxidative peptides derived from milk proteins. Int Dairy J 16, 1306-1314.

83. Szabó C, Ischiropoulos H \& Radi R (2007) Peroxynitrite: biochemistry, pathophysiology and development of therapeutics. Nat Rev Drug Discov 6, 662-680.

84. Vermeirssen V, Van Camp J \& Verstraete W (2004) Bioavailability of angiotensin I converting enzyme inhibitory peptides. Br J Nutr 92, 357-366.

85. Masuda O, Nakamura Y \& Takano T (1996) Antihypertensive peptides are present in aorta after oral administration of sour milk containing these peptides to spontaneously hypertensive rats. J Nutr 126, 3063-3068.

86. Foltz M, Cerstiaens A, van Meensel A, et al. (2008) The angiotensin converting enzyme inhibitory tripeptides IlePro-Pro and Val-Pro-Pro show increasing permeabilities with increasing physiological relevance of absorption models. Peptides 29, 1312-1320.

87. Wuerzner G, Peyrard S, Blanchard A, et al. (2009) The lactotripeptides isoleucine-proline-proline and valine-proline-proline do not inhibit the N-terminal or C-terminal angiotensin converting enzyme active sites in humans. J Hypertens 27, 1404-1409.

88. Vermeirssen V, Van Camp J, Decroos K, et al. (2003) The impact of fermentation and in vitro digestion on the formation of angiotensin-I-converting enzyme inhibitory activity from pea and whey protein. J Dairy Sci 86, 429-438.

89. Vermeirssen V, Van Camp J, Devos L, et al. (2003) Release of angiotensin I converting enzyme (ACE) inhibitory activity during in vitro gastrointestinal digestion: from batch experiment to semicontinuous model. J Agric Food Chem 51, 5680-5687.

90. Murakami M, Tonouchi H, Takahashi R, et al. (2004) Structural analysis of a new anti-hypertensive peptide ( $\beta$-lactosin B) isolated from a commercial whey product. J Dairy Sci $\mathbf{8 7}$, 1967-1974. 